\title{
Review \\ Endocrinology and hormone therapy in breast cancer Aromatase inhibitors versus antioestrogens
}

\author{
Anthony Howell ${ }^{1}$ and Mitch Dowsett ${ }^{2}$
}

${ }^{1}$ CRUK Department of Medical Oncology, University of Manchester, Christie Hospital, Manchester, UK

${ }^{2}$ Academic Department of Biochemistry, Royal Marsden Hospital, London, UK

Corresponding author: Anthony Howell, maria.parker@christie-tr.nwest.nhs.uk

Published: 6 October 2004

Breast Cancer Res 2004, 6:269-274 (DOI 10.1186/bcr945)

(C) 2004 BioMed Central Ltd

\begin{abstract}
Endocrine therapies act by either blocking or downregulating the oestrogen receptor or by reducing oestrogen concentrations around and within the cancer cell. In postmenopausal women, oestrogen suppression is achieved by inhibition of the enzyme aromatase by aromatase inhibitors (Als). Modern Als (anastrozole, letrozole and exemestane) are more potent than earlier ones and suppress oestradiol levels in plasma to virtually undetectable concentrations. Recent comparisons of Als with the most widely used oestrogen receptor blocking drug tamoxifen indicate that, in general, Als result in increased response rates and greater durations of response. Here, we summarize data supporting the difference between the two types of treatment and attempt to account for the underlying mechanisms that favour Als.
\end{abstract}

Keywords: aromatase inhibitors, breast cancer, endocrine therapy, tamoxifen

\section{Introduction}

Most endocrine therapies for breast cancer treatment and prevention depend upon inhibiting the proliferative effect of oestradiol on oestrogen receptor (ER)-positive tumour or normal mammary epithelial cells. Either oestradiol is inhibited from binding to ER by antioestrogens, or serum and tissue oestradiol concentrations are reduced by ovarian ablation in premenopausal women or by inhibition of aromatase in postmenopausal women.

Several randomized comparisons of the two approaches to endocrine therapy (ER blockade and oestradiol suppression) were conducted using older, less potent Als. Two trials that compared aminoglutethimide with tamoxifen $[1,2]$ showed no differences in rates of response or duration of response. Two other randomized trials compared the second-generation Als formestane and fadrozole with tamoxifen $[3,4]$ and showed a trend toward superiority of the Als over the antioestrogen, but this was not statistically significant. At their clinical doses, each of these three Als reduces aromatase activity by about $90 \%$. More recently aminoglutethimide was compared with the third-generation Al letrozole, which suppresses peripheral aromatase by at least 99\% [5]. Letrozole produced a higher objective response rate and longer time to progression, indicating the importance of the completeness of aromatase inhibition [6]. However, when two highly potent Als were compared (anastrozole and letrozole) [7] there was no difference between them in the primary efficacy end-point, namely time to progression, despite the fact that letrozole achieves slightly more complete inhibition of aromatase than does anastrozole [5].

It is unlikely that more potent Als than those currently available (anastrozole, letrozole and exemestane) will be developed in the foreseeable future, and thus the three Als are the treatments of choice for comparison with ER blockade to determine the most active type of endocrine therapy. In nearly all trials Als have been compared with the antioestrogen tamoxifen. This is an appropriate choice of comparator because, despite a large number of clinical trial comparisons, no other antioestrogen has been found to be superior to tamoxifen, which was introduced many years ago [8]. 
Table 1

\begin{tabular}{|c|c|c|c|c|c|}
\hline Reference & $\begin{array}{c}\text { Agent } \\
\text { administered }\end{array}$ & $\begin{array}{l}\text { Number of } \\
\text { subjects }\end{array}$ & $\begin{array}{l}\text { Response } \\
(\%)\end{array}$ & $\begin{array}{c}\text { Clinical benefit } \\
(\%)\end{array}$ & $\begin{array}{c}\text { Time to progression } \\
\text { (months) }\end{array}$ \\
\hline \multirow[t]{2}{*}{ [9] } & Letrozole & 453 & 30 & 49 & 9.4 \\
\hline & Tamoxifen & 454 & 20 & 38 & 6.0 \\
\hline \multirow[t]{2}{*}{ [13] } & Letrozole & 154 & 55 & - & - \\
\hline & Tamoxifen & 170 & 36 & - & - \\
\hline \multirow[t]{2}{*}{ [11] } & Anastrozole & 171 & 21 & 59 & 11.1 \\
\hline & Tamoxifen & 182 & 17 & 46 & 5.6 \\
\hline \multirow[t]{2}{*}{ [19] } & Anastrozole & 340 & 33 & 56 & 8.2 \\
\hline & Tamoxifen & 328 & 33 & 56 & 8.3 \\
\hline \multirow[t]{2}{*}{ [11] } & Anastrozole & 121 & 43 & 83 & - \\
\hline & Tamoxifen & 117 & 31 & 56 & - \\
\hline \multirow[t]{2}{*}{ [10] } & Exemestane & 61 & 41 & 57 & - \\
\hline & Tamoxifen & 59 & 17 & 42 & - \\
\hline
\end{tabular}

Recent clinical trials indicate that the new Als generally have greater response rates and increase median time to progression compared with tamoxifen in patients with advanced breast cancer [9-12]. These studies included some patients who had received tamoxifen as adjuvant therapy, and this might have influenced the superiority of the Als. More recently, Als were also shown to be more effective in treatment naïve patients in the neoadjuvant setting [13] and to be superior in preventing relapse as adjuvant therapy [14-16]. They may also be superior in preventing breast cancer because they reduce the incidence of contralateral breast cancer $[14,16,17]$.

\section{More tumour responses to aromatase inhibitors}

Response to endocrine treatments is best tested before surgery (neoadjuvant studies) or at first relapse, because in both situations objective tumour measurements can be taken and there is only minor confounding from previous treatments. Response rates in randomized trials comparing Als with tamoxifen in both clinical situations are summarized in Table 1. In most trials there were significantly greater objective response rates (complete plus partial remissions) and/or rates of clinical benefit (complete plus partial remissions, and stable disease for 24 weeks or more) for Als [9-12,18]. One large randomized trial comparing anastrozole with tamoxifen in advanced breast cancer found no significant advantage in terms of objective response or clinical benefit [19]. The reason for the lack of difference is not clear, but this is the response rate as compared with tamoxifen. Other small nonrandomized but carefully performed preoperative studies by the Edinburgh group [20] also found superior responses to anastrozole and letrozole as compared with tamoxifen.

\section{Longer duration of responses to aromatase inhibitors}

The duration of effectiveness of Als and tamoxifen can be assessed in randomized trials of first-line therapy in advanced breast cancer. Both anastrozole and letrozole extend the median time to progression by approximately 2-3 months compared with tamoxifen (Table 1) [9,12]. In one trial [11] the investigators reported the time to progression in all patients who had a clinical benefit response. The median time to progression in this trial for tamoxifen after clinical benefit was 7 months, whereas it was 18 months for anastrozole. Currently, no peer reviewed phase III data are published and available for exemestane, but the data outlined above indicate generally longer durations of response to Als as compared with tamoxifen. Similar differences in time to progression have been reported in animal models of human breast cancer. Long and coworkers [21] transfected MCF-7 cells with the aromatase gene and transplanted the cells into nude mice. In this model, tumour development was inhibited for 37 weeks in letrozole treated mice as compared with 16 weeks in tamoxifen treated mice. In a more recent study [22] the same group demonstrated that continuous letrozole administration caused longer tumour growth retardation than did continuous tamoxifen, tamoxifen 
Table 2

\begin{tabular}{|c|c|c|c|c|c|}
\hline \multirow[b]{2}{*}{ Phenotype } & \multicolumn{2}{|c|}{ Letrozole } & \multicolumn{2}{|c|}{ Tamoxifen } & \multirow[b]{2}{*}{$P$} \\
\hline & $n$ & RR (\%) & $n$ & RR (\%) & \\
\hline $\mathrm{ER}^{+} / \mathrm{PgR}^{+}$ & $54 / 85$ & 64 & $33 / 81$ & 41 & 0.005 \\
\hline $\mathrm{ER}^{+} / \mathrm{PgR}^{-}$ & $18 / 34$ & 53 & $16 / 41$ & 39 & 0.331 \\
\hline $\mathrm{ER}^{-} / \mathrm{PgR}^{+}$ & $2 / 4$ & 50 & $2 / 2$ & 100 & NS \\
\hline $\mathrm{ER}^{-} / \mathrm{PgR}^{-}$ & $1 / 12$ & 8 & $0 / 16$ & 0 & NS \\
\hline ErbB1 or $2^{+} / \mathrm{ER}^{+}$ & $15 / 17$ & 88 & $4 / 19$ & 21 & 0.0004 \\
\hline ErbB1 and $2^{-} / \mathrm{ER}^{+}$ & $55 / 101$ & 54 & $42 / 100$ & 42 & 0.08 \\
\hline ErbB1 or $2^{+} / \mathrm{ER}^{-}$ & $0 / 9$ & 0 & $0 / 10$ & 0 & - \\
\hline
\end{tabular}

ER, oestrogen receptor; NS, not significant; PgR, progesterone receptor; RR, response rate. Data from Ellis and coworkers [32].

switched to letrozole, or a combination of tamoxifen and letrozole. Thus, both in women with advanced breast cancer and in animal models of human breast cancer, the time to progression (time to secondary resistance) is delayed longer by Als than by tamoxifen.

\section{Why are aromatase inhibitors superior to tamoxifen?}

Superficially, one would expect little difference between the two treatment types because both effectively reduce oestrogenic stimulation of breast cancer cells. However, there are clearly major differences in the mechanisms of action of the two treatments. Greater response rates indicate that there are a group of tumours that respond to Als but not to tamoxifen. Increased time to progression using Als suggests that resistance to tamoxifen arises sooner than does resistance to Als. Unravelling the mechanisms responsible for the superiority of Als is not only of interest biologically but it may also be help to achieve further improvements in endocrine therapy in the future.

Neoadjuvant trials are most helpful with respect to investigating the mechanism responsible for the difference in effectivess between the two types of treatment because tissue before, during and immediately after treatment is available and can be assayed for potential markers of increased response using a variety of techniques. Clinical response rates according to $E R$ and progesterone receptor $(\mathrm{PgR})$ phenotype were reported in a randomized trial comparing neoadjuvant letrozole with tamoxifen [18]. Increased responses to letrozole were seen, to a similar degree, in both ER-positive/PgR-positive and ER-positive/ PgR-negative phenotypes, although for the latter phenotype the difference between the two treatments was not significant, possibly because of the small numbers included (Table 2). When response was related to HER1 (epidermal growth factor receptor) and HER2 (cErbB2) expression (in ER-positive tumours), higher response rates to letrozole were again seen in tumours positive for HER1 or HER2 and those negative for both HER1 and HER2. However, there were fewer responses to tamoxifen in the ErbB1/ErbB2-positive tumours. One potential explanation for this is that tamoxifen causes translocation of ER to oestrogen response elements of cognate genes, allowing cross-talk between growth factor and steroid pathways. In contrast, because Als reduce this interaction as a result of reduced oestradiol-stimulated ER activation, greater effectiveness in downregulating ER-dependent signalling is achieved. Consideration of how this occurs requires a description of the basic signalling sequence for ER.

Classically, both oestradiol and tamoxifen bind to the ER and cause dimerization and translocation of the receptor to the promoter region of oestrogen-regulated genes. However, whereas oestradiol activates two regions of the ER molecule (called activating function $[A F] 1$ and $A F 2$ ), tamoxifen inhibits AF2 but not AF1. AF1 remains active in the presence of tamoxifen and thus could be responsible for the partial agonist activity of the compound. AF1 contains most of the sites that are phosphorylated by growth factor activity. Tamoxifen and oestradiol cause conformational changes in the receptor that allow binding of a series of coactivator and corepressor proteins. It is thought that the relative proportions of each determine whether the ligand will act as an oestrogen or an antioestrogen for a specific gene.

Recent studies suggest that phosphorylation of coregulators is an additional mechanism of control of transcription [23]. Ligand-bound ER can also interact with other transcription factors such as activator protein-1 and nuclear factor- $\kappa \mathrm{B}$, and other proteins within the cell and the cell membrane [24]. Thus, there are multiple potential mechanisms of tamoxifen resistance, but those that 
depend on receptor dimerization and translocation are probably of the greatest importance. Resistance may be caused by increased growth factor activity via AF1 or alteration of the coactivator/corepressor ratio. An example of the former mechanism is development of tamoxifen resistance in MCF-7 cells by transfection with the gene for the ErbB2 receptor, which can be reversed by blocking activity of the receptor [25]. Recent examples of the latter mechanism are the demonstrations that increased expression of the coactivator AIB1 (activated in breast cancer 1; also known as SRC3) [26] and decreased expression of the corepressor [27] are associated with tamoxifen resistance in women with breast cancer. Other potential mechanisms of tamoxifen resistance, such as altered pharmacokinetics, differential cell uptake and receptor mutation, appear to be less important than was previously thought [23].

In patients with advanced breast cancer who progress after a response to tamoxifen, simply stopping tamoxifen can lead to tumour remission, suggesting that tamoxifen may be acting as an agonist [28]. Tamoxifen may become an agonist for MCF-7 cells growing in nude mice $[29,30]$. Initially, in this model tamoxifen inhibits growth. However, when these tumours are retransplanted into new mice tamoxifen treatment stimulates growth. In vitro, cells from tamoxifen-resistant human pleural effusions have been shown to be growth stimulated by tamoxifen. Inhibition of growth can be demonstrated by additional fulvestrant, suggesting tamoxifen agonist activity occurs via ER pathways, as expected [31].

By comparison with the multiple potential interactions after tamoxifen binding and translocation of the ER, the action of Als appears relatively simple. It is presumed that oestradiol levels are reduced to the extent that receptor dimerization and translocation do not take place to any appreciable extent. Thus, in the oestrogen responsive tumour cell, growth is abrogated. Differences in mechanisms of action of Als and tamoxifen are exemplified by changes in transcription of the oestrogen-induced genes $\mathrm{PgR}$ and $\mathrm{pS} 2$. In one neoadjuvant study letrozole reduced expression of $\mathrm{PgR}$ and $\mathrm{pS} 2$, whereas tamoxifen resulted in small increases in expression, again indicating differences from the mechanism of action of Als [32].

Resistance to Als has been directly studied in the model outlined above, in which MCF-7 cells expressing aromatase were transplanted into nude mice, treated with letrozole and the time to resistance determined. When the resistant tumours were retransplanted into new mice their growth was slowed by tamoxifen and inhibited more effectively by the pure antioestrogen fulvestrant [21]. Fulvestrant is thought to act by downregulating ER, and its activity in Alresistant tumour suggests that even at low oestradiol
Because modern Als effectively deprive tumour cells of estrogens, a surrogate method for studying the mechanism of resistance to oestrogen deprivation is to grow ERpositive human mammary tumours in oestrogen-depleted culture medium. When MCF-7 cells are placed in such media they are growth arrested for 3-6 months and then begin to regrow. When their response to oestradiol at the time of regrowth is retested, it is found that the dose-response curve is shifted to the left and maximal proliferation occurs at approximately $10^{-14} \mathrm{~mol} / \mathrm{l}$, instead of the approximately $10^{-9} \mathrm{~mol} / \mathrm{l}$ in wild-type MCF-7 cells. Proliferation at such low levels of oestradiol can be inhibited by fulvestrant, indicating that hypersensitivity occurs via an ER-dependent mechanism [33,34]. Resistance to low oestradiol concentrations is associated with several cellular changes, including enhanced HER2 receptor expression, elevated levels of insulin-like growth factor-1 receptor and ER, and increased signal transduction via the mitogen-activated protein kinase and phosphatidylinositol-3 kinase pathways [34-36].

Recent experiments reported by Santen and colleagues suggest that resistance to oestrogen deprivation could also be via membrane associated ER [36]. ER-negative cells transfected with an ER lacking a nuclear localization signal and containing a membrane localizing signal proliferated in response to oestradiol and were inhibited by fulvestrant and by an inhibitor of GTP-Ras binding to its membrane receptor (farnesylthiosalicyclic acid). Further studies are required to determine whether the major mechanism of hypersensitivity is via membrane ER or nuclear ER, or both.

In the neoadjuvant study in which letrozole was compared with tamoxifen [37], the ER was quantitated by number of cells positive and the intensity of staining. Responses to letrozole were seen in tumours with high ER-positive scores and the small number of those with low ER scores, whereas responses were not seen at low receptor scores with tamoxifen. Thus, this important study suggests that some of the increased response to Als is related to their greater activity not only in tumours that overexpress growth factor receptors but possibly also in those that have low expression of ER. Confirmation of these results and extension to other indicators of response is required before we can apply these findings clinically. Because there is a correlation between the presence of HER2 and low ER levels [38], it will be important to try to separate the dominant factor in the relationship with tamoxifen resistance in future studies.

There is also an association between the ER-positive/ PgR-negative tumour phenotype and low cell ER concentrations. In the ATAC (Arimidex, Tamoxifen Alone or in Combination) adjuvant therapy trial [39], there was a relapse-free survival advantage for anastrozole compared with tamoxifen at a median follow up of 47 months. When 
This article is part of a review series on Endocrinology and hormone therapy in breast cancer, edited by

James N Ingle and V Craig Jordan.

Other articles in the series can be found online at http://breast-cancer-research.com/articles/ review-series.asp?series=bcr_endocrinology

analyzed according to the two major receptor subgroups, ER-positive/PgR-positive (74\% of patients) and ER-positive/ PgR-negative (17\% of patients), although anastrozole was superior to tamoxifen in both groups there was a much greater difference in the ER-positive/PgR-negative subtype. The hazard ratio for the comparison for the ER-positive/ PgR-positive subtype was 0.82 (95\% confidence interval 0.65-1.03) in favour of anastrozole, whereas for the ER-positive/PgR-negative subtype the hazard ratio was 0.48 (95\% confidence interval 0.33-0.71). The greater effect in the ER-positive/PgR-negative subtype may be related to anastrozole being more effective than tamoxifen at low receptor concentrations. Also, we know from other studies that this subtype is more likely to be associated with HER1/2-positive tumours (approximately 30\% express the nuclear and the cell surface membrane receptor), as compared with approximately $10 \%$ coexpression in the ER-positive/PgR-positive subtype.

\section{Conclusion}

Increased response rates of Als as compared with tamoxifen may be related to greater responsiveness to Als in tumours with low concentrations of ER and expression of HER1 and HER2. Delayed resistance to Als is probably mediated by a delay in ER binding to gene promoters. Several biochemical pathways activated during resistance to tamoxifen and resistance to oestrogen deprivation suggest new targets for preventing resistance, including inhibitors of cell surface signal transduction pathways (inhibitors of phosphatidylinositol-3 kinase and mitogenactivated protein kinase pathways) and of farnesylation. Clinical studies combining these agents with Als herald a new era of 'endocrine' therapy (for a review of this area, see that by Ellis [40]). These benefits are now being translated into the adjuvant situation and for prevention of breast cancer. Als given immediately after surgery result in reduced rates of relapse as compared with tamoxifen [14]. Als given after 2-3 or 5 years of adjuvant tamoxifen confer additional reductions in relapse compared with tamoxifen $[15,17]$. In addition, anastrozole administration results in fewer contralateral breast cancers as compared with tamoxifen [14], suggesting that Als may be used to prevent breast cancer.

\section{Competing interests}

$\mathrm{AH}$ has served on advisory boards and given lectures for AstraZeneca and Novartis. MD has acted as a consultant and/or on advisory boards for AstraZeneca, Novartis, Pfizer and Lilly. MD has received grants from Pfizer and Lilly.

\section{References}

1. Smith IE, Harris AL, Morgan M: Tamoxifen versus aminoglutethimide versus combined tamoxifen and aminoglutethimide in the treatment of advanced breast carcinoma. Cancer Res 1982, Suppl:3430s-3433s.

2. Gale KE, Anderson JW, Tormey DC: Hormonal treatment for metastatic breast cancer. An Eastern Cooperative Group phase III trial comparing aminoglutethimide to tamoxifen. Cancer 1994, 12:1630-1638.

3. Perez Carrion R, Alberola Candel V, Calabresi F: Comparison of the selective aromatase inhibitor formestane with tamoxifen as first-line hormonal therapy in postmenopausal women with advanced breast cancer. Ann Oncol 1994, Suppl 7:19-24.

4. Thurlimann $B$, Beretta $\mathrm{K}$, Bacchi M: First-line fadrozole $\mathrm{HCl}$ (CGS-16949A) versus tamoxifen in postmenopausal women with advanced breast cancer. Prospective randomised trial of the Swiss Group for Clinical Cancer Research SAKK 20/88. Ann Oncol 1996, 7:471-479.

5. Geisler J, Haynes B, Anker G, Dowsett M, Lonning PE. Influence of letrozole and anastrozole on total body aromatization and plasma estrogen levels in postmenopausal breast cancer patients evaluated in a randomised, cross-over study. J Clin Oncol 2002, 20:751-757.

6. Gershanovich M, Chaudri HA,Campos D: Randomised trial comparing $2.5 \mathrm{mg}$ daily, $0.5 \mathrm{mg}$ daily and aminoglutethimide in postmenopausal women with advanced breast cancer. Letrozole International Control Group (AR/BC3). Ann Oncol 1998, 9:639-645.

7. Rose C, Vtoraya O, Pluzanska A, Davidson N, Gershanovich M, Thomas R, Johnson S, Caicedo JJ, Gervasio H, Manikhas G, et al.: An open randomised trial of second-line endocrine therapy in advanced breast cancer: comparison of the aromatase inhibitors letrozole and anastrozole. Eur J Cancer 2003, 39: 2318-2327.

8. Cole MP, Jones CTA, Todd IDH. A new anti-oestrogenic agent in late breast cancer: an early clinical appraisal of ICI 146474. Br J Cancer 1971, 25:270-275.

9. Mouridson H, Gershanovich M, Sun Y, Perez-Carrion R, Boni C, Monnier A, Apffelstaedt J, Smith R, Sleebom HP, Joenicke F, et al.: Phase III study of letrozole versus tamoxifen as first-line therapy of advanced breast cancer in postmenopausal women: analysis of survival and update of efficacy from the International Letrozole Breast Cancer Group. J Clin Oncol 2003, 21:2101-2109.

10. Paridaens R, Dirix L, Lohrisch C, Beex L, Nooij M, Cameron D, Biganzoli L, Cufer T, Duchateau L, Hamilton A, et al.: Mature results of a randomised phase II multicenter study of exemestane versus tamoxifen as first-line hormone therapy for postmenopausal women with metastatic breast cancer. Ann Oncol 2003, 14:1391-1398.

11. Milla-Santos A, Milla L, Portella J, Rallo L, Pons M, Rodes E, Casanovas J, Puig-Gali M: Anastrozole versus tamoxifen as first-line therapy in postmenopausal patients with hormonedependent advanced breast cancer. Am J Clin Oncol 2003, 26: 317-322.

12. Nabholtz JM, Buzdar A, Pollak M: Anastrozole is superior to tamoxifen as first-line therapy for advanced breast cancer in postmenopausal women: results of a North American multicenter randomized trial. Arimidex Study Group. J Clin Oncol 2000, 18:3758-3776.

13. Eierman W, Paepke S, Appfelstaedt J, Llombart-Cussac A, Eremin J, Vinholes J, Mauriac L, Ellis M, Lassus M, Chaudri-Ross HA, et al.: Preoperative treatment of postmenopausal breast cancer patients with letrozole: a randomised double-blind multicenter study. Ann Oncol 2001, 132:1527-1532.

14. Baum M,Cuzick J, Forbes J, Houghton J,Howell A (The ATAC Trialists Group): Anastrozole alone or in combination with tamoxifen versus tamoxifen alone for adjuvant treatment of postmenopausal women with early stage breast cancer. Results of the ATAC (Arimidex, Tamoxifen Alone or in Combination) trial efficacy and safety update analyses. Cancer 2003, 98:1802-1810. 
15. Boccardo F, Rubagooi J, Amoroso D, Mesiti M, Masoobrio M, Porpiglia M, Rinaldini M, Paladini G, Distante V, Franchi R, et al:: Anastrozole appears to be superior to tamoxifen in women already receiving tamoxifen treatment [abstract]. Breast Cancer Res Treat 2003, Suppl 1:S6.

16. Coombes RC, Hall E, Gibson LJ, Paridaens R, Jassem J, Delozier $\mathrm{T}$, Jones SE, Alvarez I, Bertelli G, Ortmann O, et al.: A randomized trial of exemestane after two to three years of tamoxifen therapy in postmenopausal women with primary breast cancer. N Engl J Med 2004, 350:1081-1092.

17. Goss PE, Ingle JN, Martino S, Robert NJ, Muss HB, Piccart MJ, Mansi J, Castiglioni M, Dongsheng T, Shepherd L, et al:: A randomized double-blind clinical trial evaluating Letrozole adjuvant therapy in postmenopausal women with early stage breast cancer completing five years of tamoxifen. $N$ Engl J Med 2003, 349:1793-1802.

18. Ellis MJ, Coop A, Singh B, Mauriac L, Llambert-Cussac A, Janicke F, Miller WR, Evans DB, Dugan M, Brady C, et al.: Letrozole is more effective neoadjuvant endocrine therapy than tamoxifen for ErbB-1- and/or ErbB-2-positive, estrogen receptor-positive primary breast cancer: evidence from a phase III randomized trial. J Clin Oncol 2001, 19:3808-3816.

19. Bonneterre J, Thurlimann B, Robertson JF, Krzakowski M, Mauriac L, Koralewski P, Vergote I, Webster A, Steinberg M, vonEuler M: Anastrozole versus tamoxifen as first line therapy for advanced breast cancer in 668 postmenopausal women: results of the Tamoxifen or Arimidex Randomized Group Efficacy and Tolerability Study. J Clin Oncol 2000, 18:3748-3757.

20. Dixon JM, Love CDB, Renshaw L, Bellamy C, Cameron DA, Miller WR, Leonard RCF: Lessons from the use of aromatase inhibitors in the neoadjuvant setting. Endocr Relat Cancer 1999, 6:227-230.

21. Long BJ, Jelovac D, Thiantnawat A, Brodie AM: Effect of second line antiestrogen therapy on breast tumour growth following first line treatment with the aromatase inhibitor letrozole: long term studies using the intratumoural aromatase model. Clin Cancer Res 2002, 8:2738-2388.

22. Long BJ, Jelovac D, Pherson N, Ragaz J, Goloubeva G, Brodie A: Therapeutic atrategies using the aromatase inhibitor letrozole and tamoxifen in a breast cancer model. J Natl Cancer Inst 2004, 96:465-465.

23. Schiff R, Massarweh S, Shou J, Osborne CK: Breast cancer endocrine resistance: how growth factor signalling and estrogen receptor coregulators modulate response. Clin Cancer Res 2003, 9:447S-454S.

24. Nemere I, Pietras RJ, Blackmore PF: Membrane receptors for steroid hormones: signal transduction and physiological significance. J Cell Biochem 2003, 88:438-445.

25. Kurokawa $\mathrm{H}$, Arteaga $\mathrm{CL}$ : ErbB (HER) receptors can abrogate antiestrogen action in human breast cancer by multiple signaling mechanisms. Clin Cancer Res 2003, 9:511S-515S.

26. Osborne CK, Bardou V, Hopp TA, Chamness GC, Hilsenbeck SG, Fuqua SAW, Wong J, Allred DC, Clark GM, Schiff R: Role of the estrogen receptor coactivator AIB1 (SRC-3) and HER$2 /$ neu in tamoxifen resistance in breast cancer. $J$ Natl Cancer Inst 2003, 95:353-361.

27. Girault I, Lerebours F, Amarir S, Tozlu S, Tubiana-Hulin M, Lidereau R, Bieche I: Expression analysis of estrogen receptor coregulators in breast carcinoma: evidence that NCOR1 expression is predictive for the response to tamoxifen. Clin Cancer Res 2003, 9:1259-1266.

28. Howell A, Dodwell D, Anderson H, Redford J: Response after withdrawal of tamoxifen and progestogens in advanced breast cancer. Ann Oncol 1992, 3:611-617.

29. Osborne KO, Coronado-Heinsohn EB, Hilsenbeck SG, McCue $\mathrm{BL}$, Wakeling AE, McClelland RA, Manning DL, Nicholson RI: Comparison of the effects of a pure steroidal antiestrogen with those of tamoxifen in a model of breast cancer. J Natl Cancer Inst 1995, 87:746-750.

30. Gottardis MM, Jiang MH, Jordan VC: Inhibition of tamoxifenstimulated growth of an MCF-7 tumor variant in athymic mice by novel steroidal antiestrogens. Cancer Res 1989, 49:40904093.

31. DeFriend D, Anderson E, Bell J, Wilks DP, West CML, Howell A: Effects of 4-hydroxytamoxifen and a novel pure antioestrogen (ICl 182780) on the clonogenic growth of human breast cancer cells in vitro. Br J Cancer 1995, 70:204-221.
32. Ellis MJ, Coop A, Singh B, Tao Y, Liombart-Cussac A, Janicke F, Mauriac L, Quebe-Fehling E, Chaudri-Ross HA, Evans DB, et al:: Letrozole inhibits tumor proliferation more effectively than tamoxifen independent of HER1/2 expression status. Cancer Res 2003, 63:6523-6231.

33. Masamura S, Santner SJ, Heitjan DF, Santen RJ: Estrogen deprivation causes estrogen hypersensitivity in human breast cancer cells. J Clin Endocrinol Metab 1995, 80:2918-2925.

34. Martin LA, Farmer I, Johnston SRD, Ali S, Marshall C, Dowsett M: Enhanced estrogen receptor (ER) $\alpha$, ERBB2, and MAPK signal transduction pathways operate during the adaptation of MCF7 cells to long term estrogen deprivation. J Biol Chem 2003, 278:30458-30468.

35. Bernstein LM, Zheng $H$, Yue W, Wang J-P, Lykkes feldt AE, Naftolin F, Harada N, Shanabrough M, Santen RJ: New approaches to the understanding of tamoxifen action and resistance. Endocr Relat Cancer 2003, 10:267-277.

36. Santen RJ, Song RX, Zhang Z, Kumar R, Jeng M-H, Masamura S, Yue $W$, Berstein L: Adaptive hypersensitivity to estrogen: mechanism for superiority of aromatase inhibitors over selective estrogen receptor modulators for breast cancer treatment and prevention. Endocr Relat Cancer 2003, 10:111-130.

37. Allred DC, Harvey JM, Berardo M: Prognosis and predictive factors in breast cancer by immunohistochemical analysis. Mod Pathol 1998, 11:155-168.

38. Konecny G, Pauletti G, Pegram M, Untch M, Dandekar S, Aguilar Z, Wilson C, Rong HM, Bauerfeind I, Felber M, et al:: Quantitative association between HER/neu and steroid hormone receptors in hormone receptor-positive primary breast cancer. $J$ Natl Cancer Inst 2003, 95:142-153.

39. Dowsett M, on behalf of the ATAC Trialists Group: Analysisof time to recurrence in the ATAC trial according to estrogen receptor and progesterone receptor status [abstract]. Breast Cancer Res Treat 2003, Suppl 1:S27.

40. Ellis M: Overcoming endocrine therapy resistance by signal transduction inhibition. Oncologist 2004, Suppl 3:20-26. 